\title{
OBITUARY
}
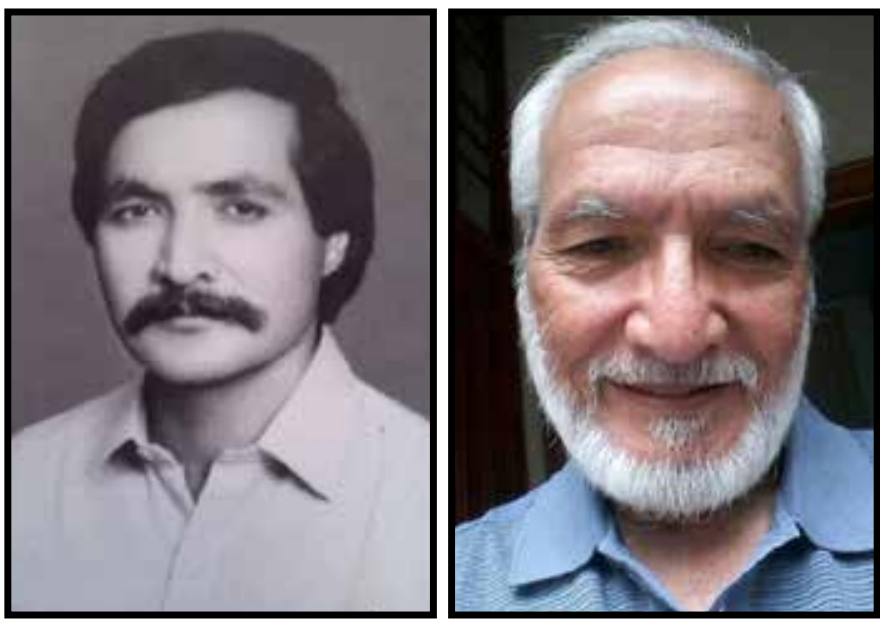

\section{Dr Manzoor Ellahi}

The First month of 2020 took the life of another very humble and noble anesthesiologist. He was a kind-hearted person, who only spoke when very essential. Dr Manzoor Ellahi breathed his last on 11th January 2020.

He was born on 27th March 1944. He qualified MBBS from Nishtar Medical College Multan and soon joined King Edward Medical College / Mayo Hospital, Lahore, from where he successfully completed his training in anesthesiology and obtained Diploma in Anesthesia (DA). He served as a busy practicing anesthesiologist in different hospitals of Rawalpindi, and even run a pain clinic in the evening time. Dr Manzoor Ellahi was a very active, energetic and bold anesthesiologist of the Rawalpindi city. But he never left his great love for humanity, and always helped poor and needy patients.

He met a tragic road traffic accident (RTA) on 28th of December 2019 while on his way to AL Ehsan Hospital Rawalpindi, rushing for an urgent call for anesthesia in early hours of the morning. The injuries proved fatal and took his life on 11th January 2020. He is survived by his wife and two sons.

By: Dr Tariq Malik,

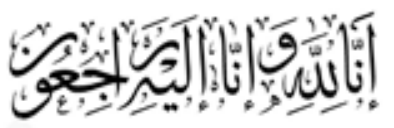

Emergency Physician,

National Guards Health Affairs,

Taif (Saudi Arabia).

DOI: https://doi.org/10.35975/apic.v24i1.1241 